\title{
Continuous dynamic response along a pre-existing structural discontinuity induced by the 2001 eruption at Mt. Etna
}

\author{
Salvatore Gambino \\ Istituto Nazionale di Geofisica e Vulcanologia, Sezione di Catania, Piazza Roma 2, 95123 Catania, Italy
}

(Received September 5, 2003; Revised January 26, 2004; Accepted March 23, 2004)

\begin{abstract}
The intrusive process of the $2001 \mathrm{Mt}$. Etna eruption was accompanied by marked ground deformation and relevant seismic activity recorded between 12 and 17 of July (INGV-CT, 2001). At the same time, extensometer data evidenced the re-activation of a dry surface failure zone on the high south-eastern sector of Mt. Etna; this fracture system, formed in 1989, has been related to the propagation of a shallow blade-like dike along a NNESSW discontinuity (Bonaccorso and Davis, 1993; Bianco et al., 1998). The NNW-SSE discontinuity represents a complex low cohesion structure in which deformation may concentrate. Displacement measurements recorded on the surface fracture and the constraints obtained from seismicity show that the intrusion phase of the 2001 eruption has forced the NNE-SSW structure to move continuously with prevalent left-lateral displacement from a depth of 2-2.5 km b. s. 1. to the surface with a compositive slip of about 3-5 centimeters.
\end{abstract}

Key words: Rod strainmeter, volcanic fractures, seismicity, Mt. Etna 2001 eruption, ground displacement.

\section{Introduction}

In active volcanic areas, such as Mt. Etna, changes in the stress field induced by magma intrusion play a fundamental role in the dynamics of pre-existing local structural discontinuities (i.e. Ferrucci, 1995; Elsworth and Voight, 1995; Ukawa and Tsukahara, 1996; Patanè and Privitera, 2001; Bonaccorso and Patanè, 2001).

The growth and dynamics of Mt. Etna is controlled by two main fault systems with NNW-SSE and NE-SW strikes (LoGiudice et al., 1982; Bonaccorso et al., 1996) (Fig. 1(A)). The NNW-SSE system is a lithospheric discontinuity separating the continental African platform from the oceanic Ionian Basin and extends from Malta Island to the Tyrrhenian Sea. This system has its main tectonic surface evidences in the "Timpe" faults system and represents a preferential path for lateral eruptions of Mt. Etna (LoGiudice et al., 1982; Bonaccorso, 2001).

The NE-SW fault system (Messina-Fiumefreddo line) extends from Southern Calabria and Straits of Messina to Mt. Etna (Monaco et al., 1997).

Local seismicity is often characterized by swarms clustered along the two main structural trends (Bonaccorso et al., 1996; Gresta et al., 1998; Patanè and Privitera, 2001); Patanè et al. (1994) and Bonaccorso and Patanè (2001) have also evidenced how the action of intrusive episodes is able to dislocate pre-existing fault system structures on Mt. Etna, causing strong seismic releases.

In September 1989, an eruptive NE-SW trending fracture system affected the eastern flank, while a NNW-SSE "dry" fracture system (without eruptive fenomena) characterized the southern flank of Mt. Etna (Frazzetta and Lanzafame,

Copy right(c) The Society of Geomagnetism and Earth, Planetary and Space Sciences (SGEPSS); The Seismological Society of Japan; The Volcanological Society of Japan; The Geodetic Society of Japan; The Japanese Society for Planetary Sciences; TERRAPUB
1990; Bonaccorso and Davis, 1993) (Fig. 1(B)).

During the successive years, the dry fractures have shown minor signs of re-activation (Bonaccorso et al., 1993; Obrizzo et al., 1993). In 1994, a network of rod strainmeters was installed to monitor the dynamics of the NNW-SSE fractures.

The 2001 eruption, occurring eight years after the preceding lateral eruption, has been characterized by a fast vertical dike emplacement that crossed the entire volcanic edifice below the summit craters area (INGV-CT, 2001).

Between 12-17 July 2001, the final phase of the eruptive dike intrusion was accompanied by a significant reactivation of the 1989 fracture and by a considerable seismicity distributed along a narrow NNW-SSE oriented band. This paper discusses one of the few examples of applying the rod strainmeter measurement technique to volcanic areas; by integrating surface displacement measurements and the constraints deduced by seismicity, the paper evidences that the 2001 intrusion process has forced a continuous dynamic response of a pre-existing NNE-SSW structure on the high south-eastern flank of Mt. Etna.

\section{The 1989 Fracture}

On September 11, 1989, after four months of strombolian activity at the summit craters, effusive activity began on Mt. Etna and lasted about a month.

The 1989 eruption of Mt. Etna was characterized by the formation of two fracture systems, striking NE-SW and NNW-SSE, and both starting from the SE Crater on September, 24 (Frazzetta and Lanzafame, 1990).

While the NE-SW fractures were followed by effusive activity, the NNW-SSE fracture opened for a length of 7 $\mathrm{km}$ without eruptive phenomena. However, an increase of the $\mathrm{CO}_{2}$ flux was recorded on the fracture field. Between September 27 and October 3, the fracture system propagated until it reached and cut the SP 92 provincial road (Zafferana- 


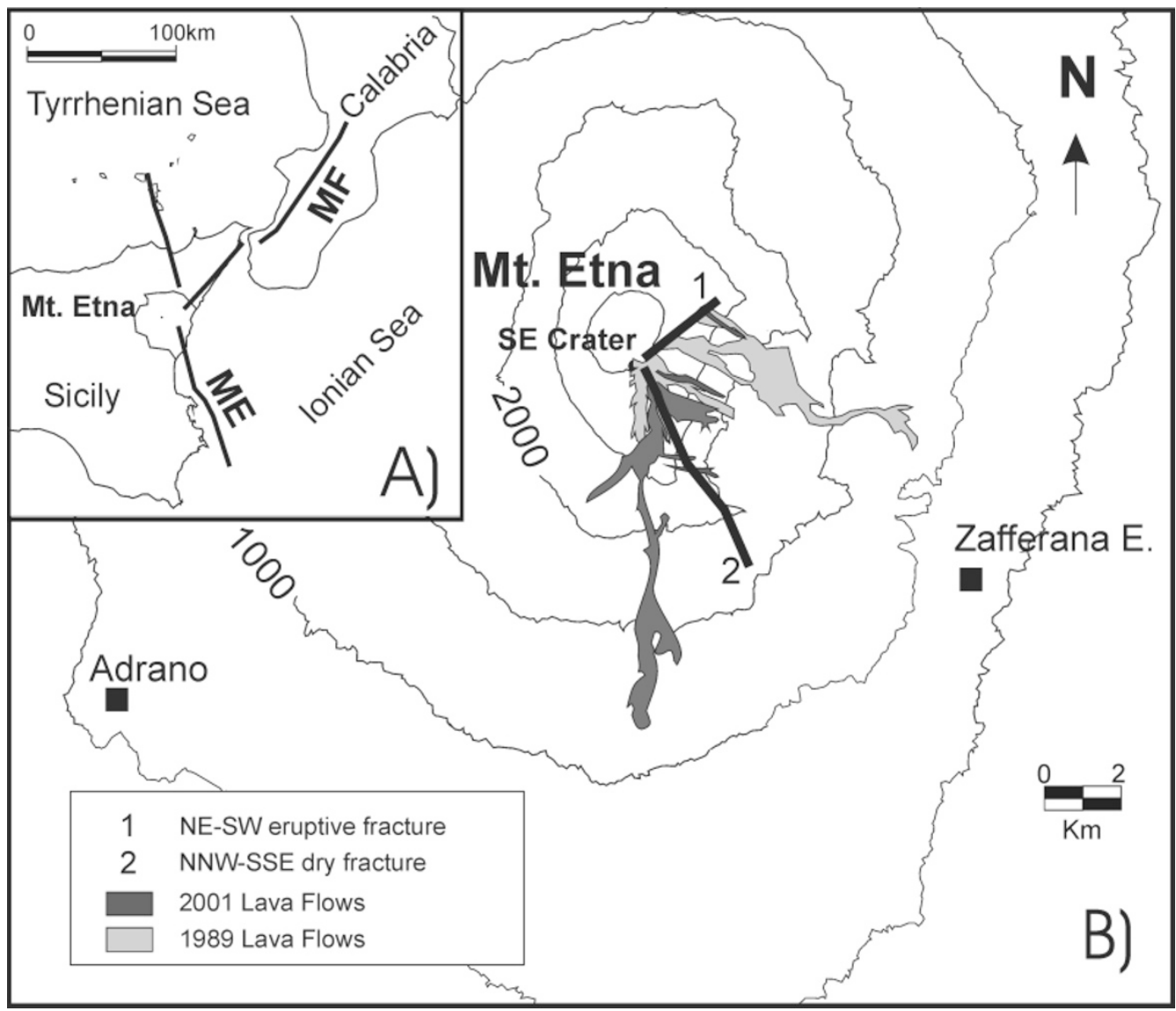

Fig. 1. A) Map of main regional fault systems: $M F=$ Messina-Fiumefreddo fault system, $M E=$ Malta Escarpment. B) Location map of the fracture systems opening during the 1989 eruption.

Rifugio Sapienza), near the 1792 effusive mouth, and continued southward for another $700 \mathrm{~m}$ (Fig. 2).

The southern branch of the NNW-SSE fracture system falls within a geodimeter trilateration network (South EDM Network) measured annually since 1987 (Bonaccorso et al., 1995). During the 1989 eruption, variations of tens of centimeters (Bonaccorso et al., 1990) were measured on the network lines directly regarding the fracture (see EDM geodetic points in Fig. 2).

The formation of the 1989 "dry" fracture was interpreted either as the effect of a tensile surface dislocation (depth = $1 \mathrm{~km}$ ) (Bonaccorso and Davis, 1993) caused by the intrusion of a dike, or as the result of a deeper magmatic injection (Ferrucci et al., 1993).

Bianco et al. (1998) interpreted this fracture as the surface expression of a blade-like dike $1.0-1.5 \mathrm{~km}$ depth.

Del Negro and Ferrucci (1998) demonstrated that the magnetic anomalies recorded across the fracture between 1989 and 1992 were compatible with a shallow dike intrusion and its successive cooling. The 1989 fracture represents a discontinuity that, during the 1991-93 eruption and afterwards, showed signs of activity. In fact during the 1991-93 eruption, repeated measurements of the EDM lines revealed clear deformations (Bonaccorso et al., 1993) of the area. In the same period, gravity data variations were also recorded (Budetta et al., 1993; Budetta et al., 1994).

Precise levelling discrete measurements (yearly) revealed, between 1990 and 1998, a subsidence along the line crossing the fracture of some millimeters/year (Obrizzo et al., 1993; Obrizzo, 1998; Obrizzo, 2000). A network of rod extensometers was installed in 1994 with a configuration of 4 instruments located on the fracture sector above the provincial road SP 92 (Fig. 2).

\section{Extensometers}

Wire and rod extensometers are common instruments developed to continuously monitor ground displacements such as landslides or dams. They are also employed to monitor active fault creep (creepmeters). In particular, as concerns the direct measurement of creep movement along the fault, this is a strain measurement method that has been applied for decades along segments of the San Andreas Fault in Central California (Bilham, 1989; Bilham and Whitehead, 1997) and also in other areas (Lee et al., 2000).

Displacement meters have also been used in volcanic areas to continuously monitor crack movements (e.g. the crater floor at Mt. St. Helens; Iwatsubo et al., 1992).

In 1994, two clusters of extensometers, each composed of 4 three-directional rod-type instruments, were set up on the 1989 fracture and on some sectors of the PernicanaProvenzana active fault on the NNE flank of the volcano (Fig. 2), which is also characterized by creep dynamics (Azzaro, 1997). In particular, the 1989 fracture sensors are situated at heights between 1680 (EE4) and $1730 \mathrm{~m}$ a. s. 1. (EE1) covering a $250 \mathrm{~m}$ stretch of the fracture, which is characterized by a "narrow graben-like" structure limited by two 


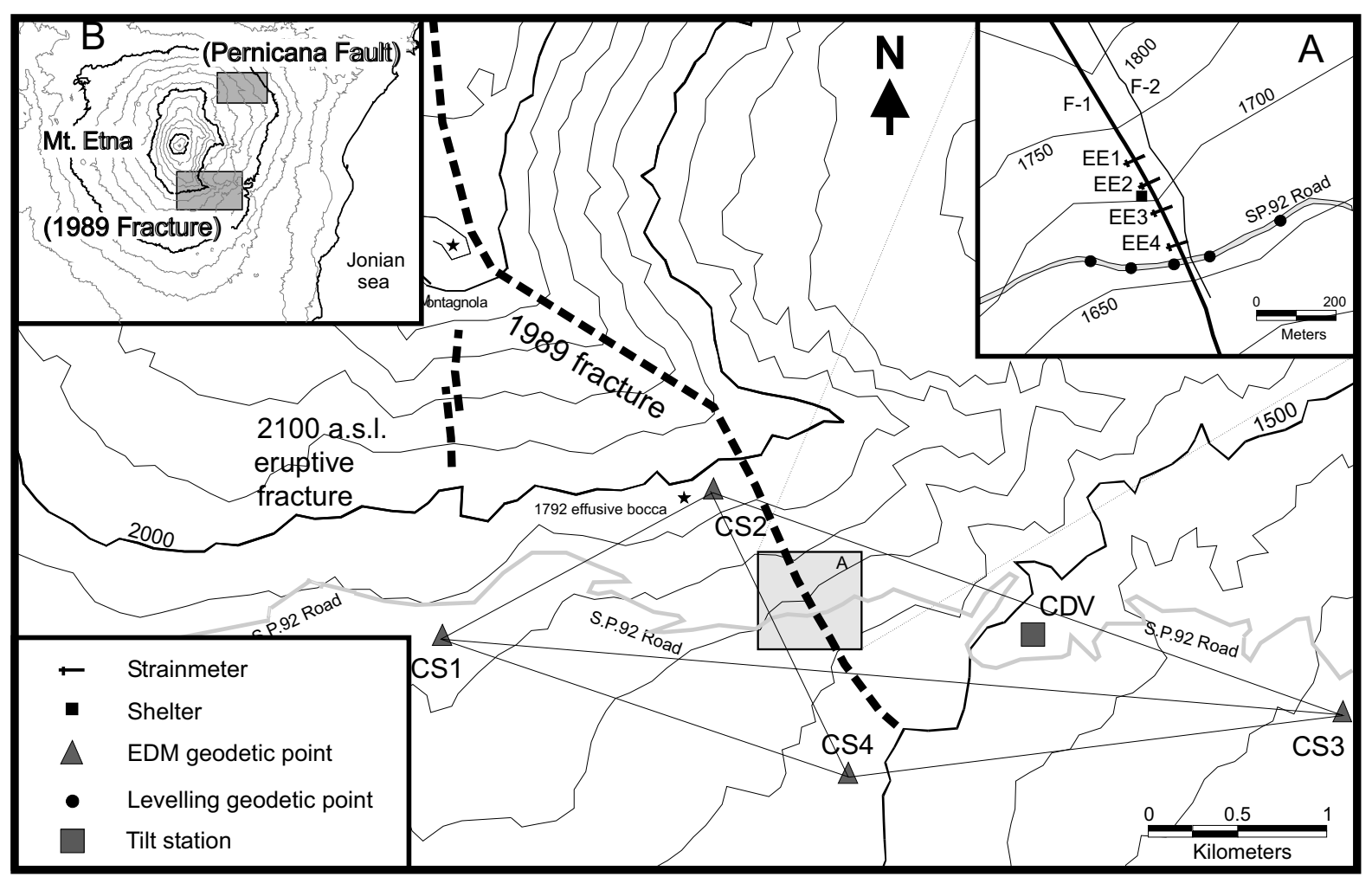

Fig. 2. Location map of 1989 fractures southern sector. The inset (A) shows the rod-strainmeter network and levelling points near the fractures. Etna map (inset B) reports the location of the Pernicana-Provenzana fault network.
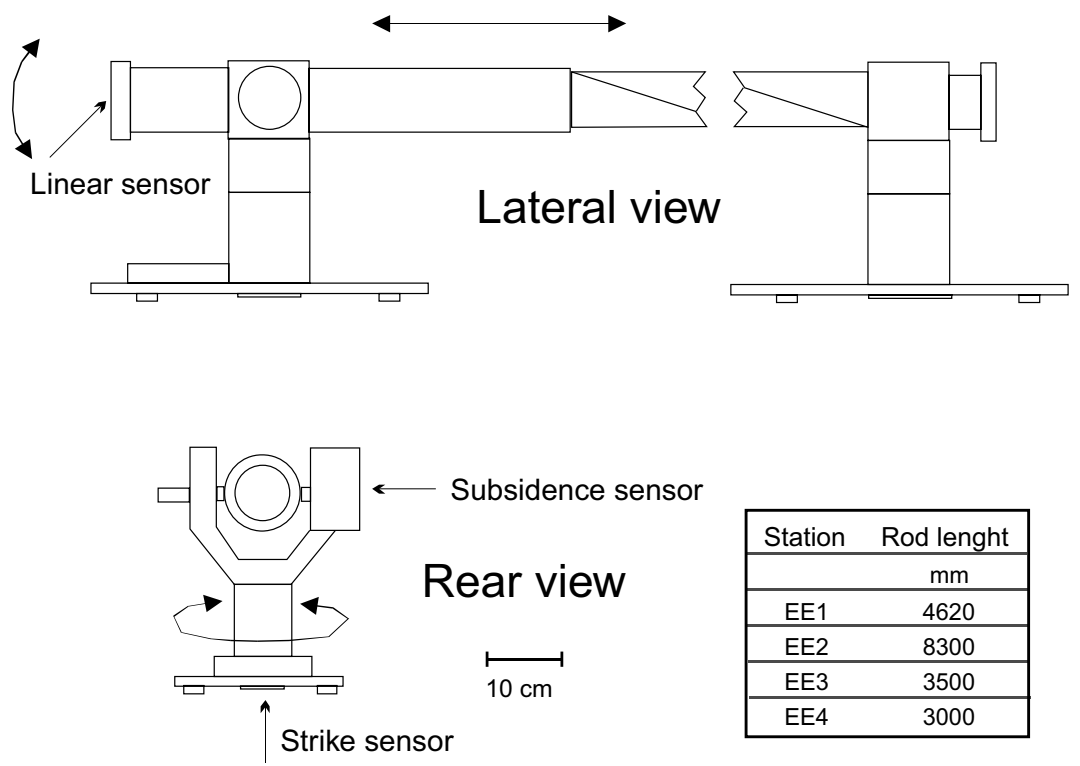

Fig. 3. Scheme of the displacement meter. Rod lengths of the instruments are reported.

main normal faults (only 9 meters apart at the SP 92 road) (Frazzetta and Lanzafame, 1990). The western discontinuity (F-1 in Fig. 2(A)), on which the network is focussed, has shown, during the 1989 crises, higher displacement and, in particular, some tens of centimeters of opening and about 10 $\mathrm{cm}$ of throw (Frazzetta and Lanzafame, 1990).

\subsection{Instrument and sensor}

The rod-type extensometer (Fig. 3) comprises 2 coaxial cylindrical steel bars of variable length, having a longitudinal travel of $500 \mathrm{~mm}$, anchored on two swiveling pivots.
The rods are free to move both horizontally and vertically, thus recording the component with respect to strike and subsidence.

Regarding the electronics, the instrument comprises three resistance potentiometers, with virtually infinity resolution, electrically isolated, waterproof housed in an anchorage (Fig. 3). Data acquisition is centralized in a shelter equipped with solar panels and a radio system capable of sending data via radio-link to Catania. The control datalogger is programmed for 24-data/day sampling and includes each of the 


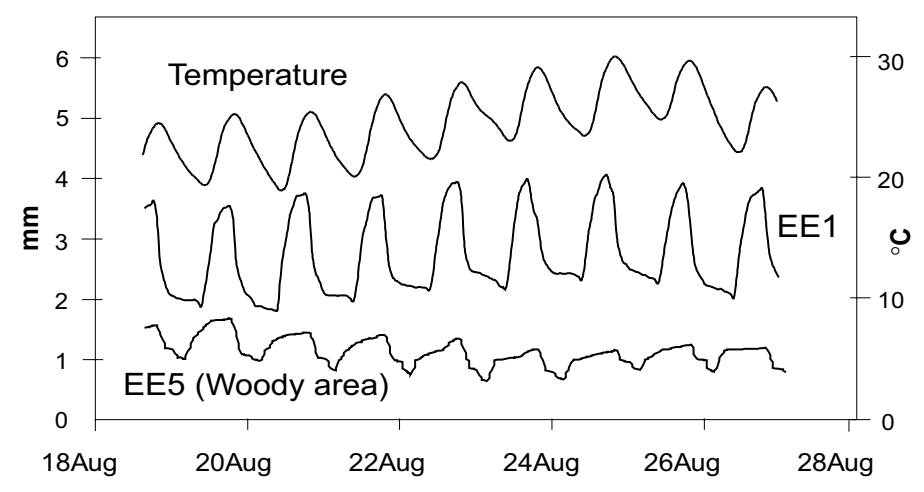

Fig. 4. Daily variation of distance at EE1 (1989 fracture system) and EE5 (Pernicana fault) stations. Air temperature recorded on 1989 fracture area is also reported.

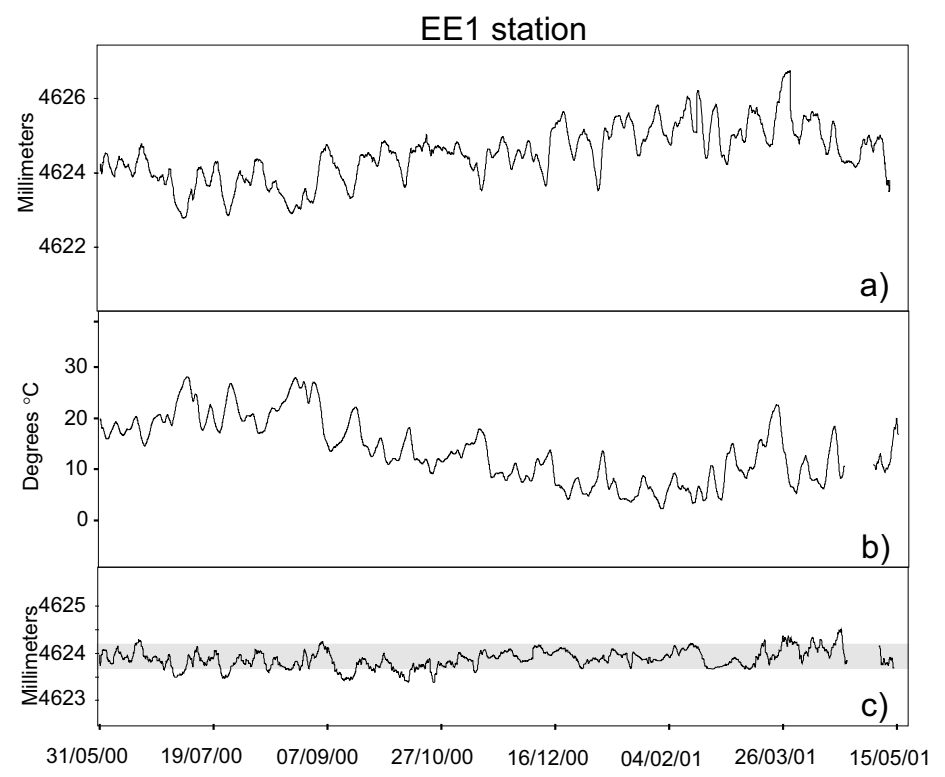

Fig. 5. Distance trend (a) and air temperature (b) recorded at EE1 station; data filtered from the high frequency thermal noise (diurnal) by applying a mobile average of 36 samples (1.5 days) one hour sliding. Distance trends corrected of temperature effects (c) over the period June $2000-$ May 2001. Confidence limits are indicated by the shadowed area.

linear and rotary components, air temperature, and battery converter voltages.

Unfortunately, between 1995 and 1999, monitoring activity was neglected due to technical difficulties. During 2000, a phase of check and maintenance of the two networks enabled having 3 stations in acquisition (EE1, EE2 and EE4).

Tests carried out in the laboratory and on site have revealed the good response (precision $=0.02 \mathrm{~mm}$ ) of the linear sensors to precise variations in the length of the bar, whereas they have detected a very low precision $(3-10 \mathrm{~mm})$ of the rotating sensors.

Data of rotary sensors are capable of detecting only large variations and an improvement in the quality of these data by substituting the sensors with other more stable and precise ones is foreseen in the future.

\subsection{Thermal effects}

Because instruments are installed on the surface, they are affected by noise induced by the changes in daily and seasonal temperatures (Lee et al., 2000).

Thermal variations in distance measurements (linear sensors) are mainly induced by contraction and expansion phe- nomena of the rods, while both the temperature effects on the electrical components of the instrumentation, as well as the thermoelastic effects on the surrounding rocks are negligible (around $10^{-3} \mathrm{~mm}$ ) (Harrison and Herbst, 1977).

The stations constituting the F-1 network of Fig. 2(A) on the fracture are directly exposed to the sun. The variations in distance recorded are characterized by daily fluctuations of around $1.5 \mathrm{~mm}$; the same instruments positioned in woody areas (on the Pernicana fault Fig. 2(B)) show less variations (0.5 mm) (Fig. 4).

In general, the daily temperature oscillations do not represent a significant aspect with regard to understanding the general trend of the signal and are therefore removed by filtering the original data. Figure 5(a) reports the trend of the distance filtered through a 36 hour mobile average (1 hour sliding). The higher amplitudes of the signal are relatively well correlated with the temperature variations (Fig. 5(b)). Distance vs. temperature linear regression has been computed considering one year (May 2000-May 2001) of the smoothed signals by least square approximation, obtaining a coefficient of $-0.11 \mathrm{~mm} /{ }^{\circ} \mathrm{C}( \pm 0.02)$ for EE1 and -0.20 


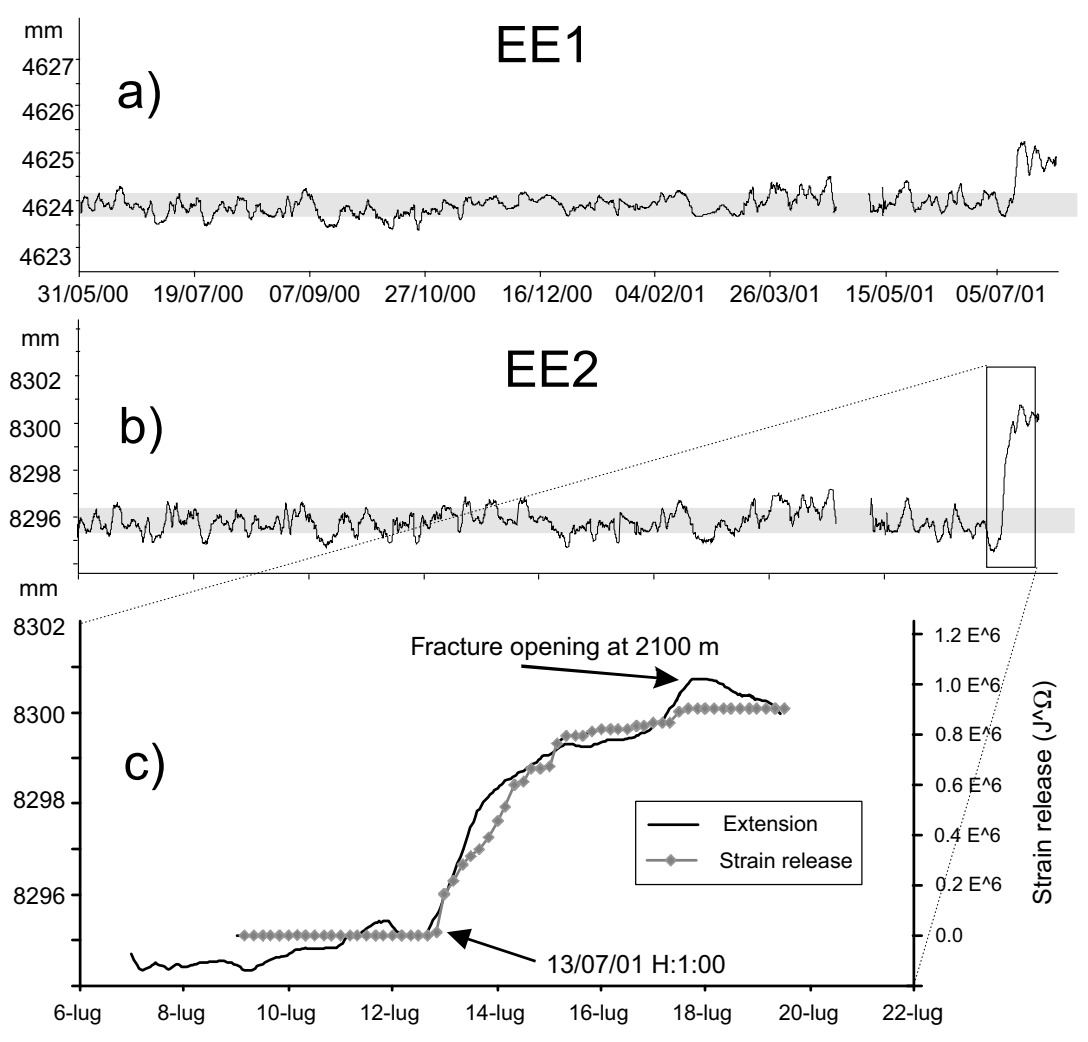

Fig. 6. Distance trends corrected of temperature effects at EE1 (a) and EE2 (b) stations over the period June 2000-August 2001. The inset (c) shows the variation recorded at EE2 during the 2001 dike intrusion phase (13-17 of July). The strain release from seismic data is also reported. Confidence limits are indicated by the shadowed areas.

$\mathrm{mm} /{ }^{\circ} \mathrm{C}( \pm 0.03)$ for EE2 distance measurements. Estimated standard error of distances with temperature is $0.23 \mathrm{~mm}$ for $\mathrm{EE} 1$ and $0.37 \mathrm{~mm}$ for EE2.

The expected noise due to thermic effects has been subtracted from the signals obtaining a clear reduction of the fluctuations (Fig. 5(c)).

\subsection{Surface displacement at the $\mathbf{1 9 8 9}$ fracture during the 2001 eruption}

On 17 July 2001, lava began pouring out from the slopes of Mt. Etna. The eruption was characterized by the opening of a $7 \mathrm{~km}$-long field of fractures that affected the summit of the volcano from north $(2600 \mathrm{~m}$ a. s. 1.) to south $(2100 \mathrm{~m}$ a. s. 1.) (INGV-CT, 2001; Billi et al., 2003).

The $2001 \mathrm{Mt}$. Etna flank eruption was characterized by a fast upward propagation dike intrusion along a north-south direction. Bonaccorso et al. (2002) modeled the marked ground deformation measured on tilt and GPS permanent networks, obtaining a tensile crack source $2 \mathrm{~km}$ a. s. 1 . with an opening of 3 meters. The eruption modalities are different from the 1989 and 1991-93 eruptions, in which the dikes propagated from the craters area to southward, usually along preferential directions (NNW-SSE) (Bonaccorso, 2001).

The final phases of the 2001 dike intrusion (13-17 of July) were accompanied both by pre-eruptive fracturing (the Cisternazza graben) at 2400-2700 m a. s. 1. and by a dynamic response of the 1989 fissure observed by Lanzafame et al. (2003). Data from extensometers and seismic networks were the only that may detect the reactivation of this preexisting structure; in fact the marked variations caused by dike propagation on tilt (tens of microradians), EDM and GPS networks (tens of centimeters) (Bonaccorso et al., 2002) precluded the possibility to reveal, on these devices, the minor effects related to the NNW-SSE structure strike movement.

From 01:00 GMT 13 July, strainmeters began recording variations (Fig. 6) indicating the reactivation of the fracture, which stopped on 17 July in coincidence with the aperture of the eruptive fractures at $2100 \mathrm{~m}$ a. s. 1. (Fig. 1). The linear sensor at EE1 station measured $1.5 \mathrm{~mm}$ and at EE2 station $4.0 \mathrm{~mm}$ of total opening. Strike and dip components, even if characterized by low precision, measured displacements up to some centimeters particularly in the first 24 hours (Fig. 7). In particular, strike components recorded about 4.5 $\mathrm{cm}( \pm 0.5)$ at EE1 and $3.0 \mathrm{~cm}( \pm 1.0)$ at EE2 of left lateral slip; while the dip component measured a smaller variation (up to $1 \mathrm{~cm}$ ). Unfortunately technical problems caused the lack of data at EE4 station.

\section{Seismicity and Its Relationships with the Surface Displacement}

The intrusive phase and the opening of the eruptive fractures of the $2001 \mathrm{Mt}$. Etna eruption were accompanied by an important seismic activity recorded on 12-17 of July (INGVCT, 2001; Patanè et al., 2003).

\subsection{Locations and seismic strain release}

The INGV local permanent seismic network detected, over five days, a total of $2645 M_{d}>1.0$ earthquakes, 62 with $M_{d} \geq 3.0$, the maximum magnitude being 3.9.

The network comprises 52 short-period stations (44 are equipped with vertical geophones and 8 with three-component geophones ( 2 of which with broad-band high-dynamic sen- 

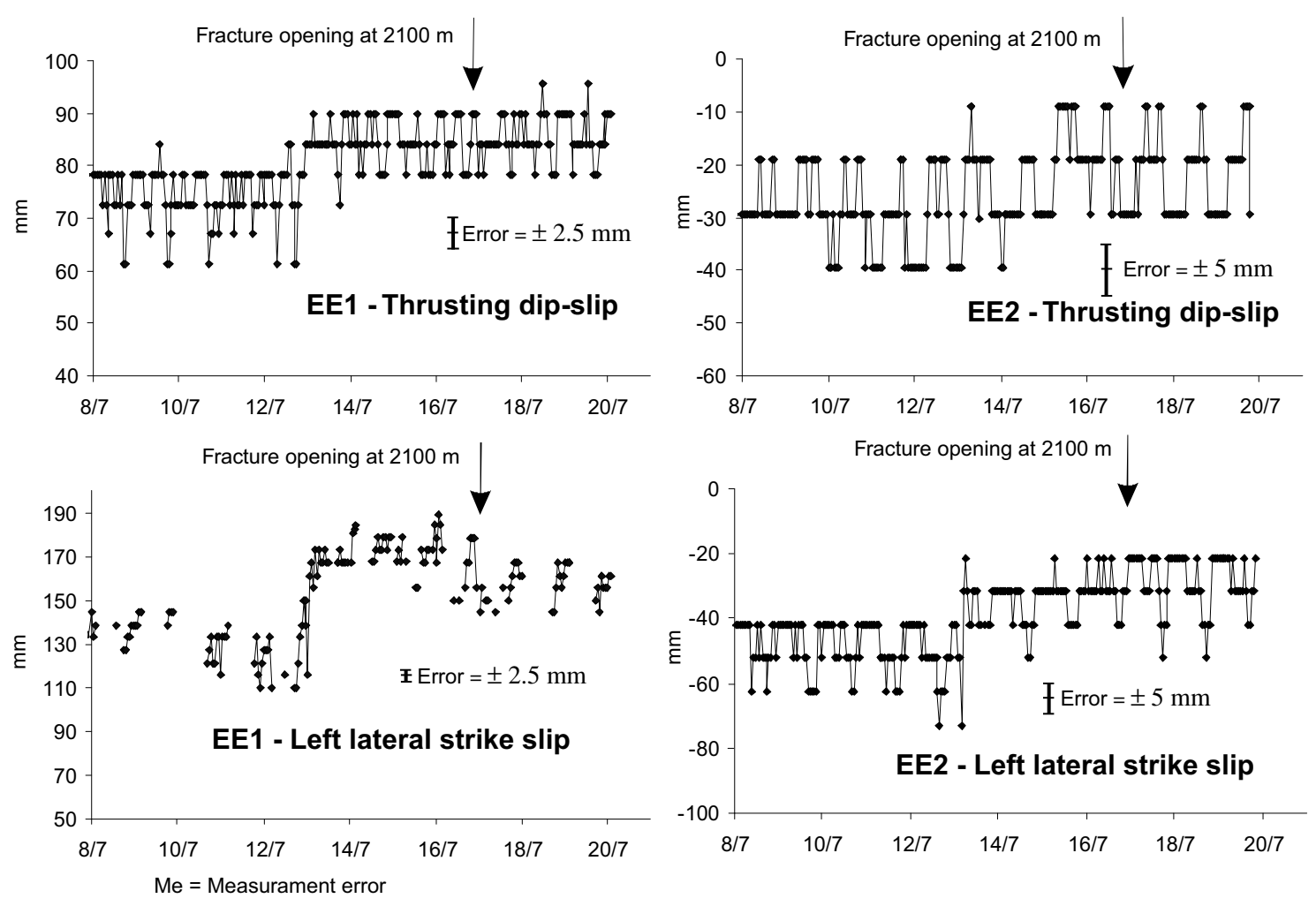

Fig. 7. Strike and dip component recorded at EE1 and EE2 stations.

sors). Figure 8 reports the location of about 350 events with $M_{d} \geq 2.0$. The locations were obtained using HYPOELLIPSE code (Lahr, 1989), which takes into account the difference in altitude of the seismic stations with a $1 \mathrm{D}$ velocity model derived from Hirn et al. (1991). The accuracy of locations ranges between 0.2 and $1 \mathrm{~km}$ for the epicentral coordinates, and between 0.3 and $1.4 \mathrm{~km}$ for the focal depth (Patanè et al., 2003).

Seismicity has affected the southern sector of Mt. Etna and is clustered in two precise areas (A and B in Fig. 8). The main seismic cluster (A) corresponds to the location of the eruptive fractures and the dike modeled with deformation data (Bonaccorso et al., 2002).

The remaining seismicity is the result of the activation of pre-existent local structural discontinuities caused by the stress changes induced by the 2001 dike intrusion (Patanè $e t$ al., 2003). In particular, sparse and strong (with $M_{\max }=3.9$ ) earthquakes have affected the SW flank, while the seismicity of SE flank is mainly clustered in close proximity to the southern sector of the 1989 fracture (B cluster in Fig. 8).

The B cluster has been analyzed in detail; it consists of 90 located events recorded from 12 to 17 July and characterized by magnitudes ranging between 2.0 and 3.5 (13 events with $M_{d}>3.0$ ). The oriented profile (Fig. 9) indicates that this seismicity is approximately distributed along a narrow band, striking about NNW-SSE, dip 70-80 E, with an extension of 3-4 km length and $4 \mathrm{~km}$ width (about $15 \mathrm{~km}^{2}$ ), which is concentrated east of the 1989 fracture on the surface.

The seismic strain release, calculated on the 90 events of the cluster B, as $\sqrt{E}$ with the following relationship (Richter, 1958):

$$
\log E=9.9+1.9 M_{d}-0.024 M_{d}^{2}
$$

shows that about $75 \%$ of strain was released before July 15 ; the cumulative strain release recorded over the period 9-20 of July is reported in Fig. 6.

\subsection{Focal mechanisms and source parameters}

A FPS analysis (Fig. 9) was performed to investigate the mechanisms of the B cluster seismicity. The FPFIT algorithm (Reasenberg and Oppenheimer, 1985) has been used to plot first-motion data and evaluate nodal planes for 12 of the more energetic events $\left(M_{d} \geq 2.6\right)$.

The significance of FPS is correlated to hypocentral location parameters, distribution of polarity on the focal sphere and knowledge of the medium velocity.

Location parameters of the selected events (Table 1) show horizontal and vertical errors $\leq 0.5 \mathrm{~km}, \mathrm{RMS} \leq 0.20 \mathrm{~s}$ and azimuthal gap $<100$; the adopted Hirn's velocity model has shown the best results in Mt. Etna FPS studies with respect to other models (Patanè and Privitera, 2001).

The data-set comprises all the events with depth $\geq 0.8 \mathrm{~km}$ a. s. 1., number of $P$-onsets $>12$, focal plane incertitude $<20^{\circ}$ and unique solution. For these earthquakes, a test has been made to verify the solution consistence by changing the depth inside the location errors (Fig. 9).

Focal solutions generally show left lateral strike-slip mechanisms along a plane ranging from NNW-SSE to NNESSW with sub-vertical dip; different hypocentral depths involve no substantial changes in focal solutions.

An estimate of the whole seismic moment release $\left(M o_{\text {tot }}=8.5 \cdot 10^{22}\right.$ dyne-cm $)$ associated with B cluster was obtained using the empirical law (Patanè et al., 1995; Bonaccorso et al., 1996):

$$
M o=18.3+1.0 \cdot M_{d}
$$




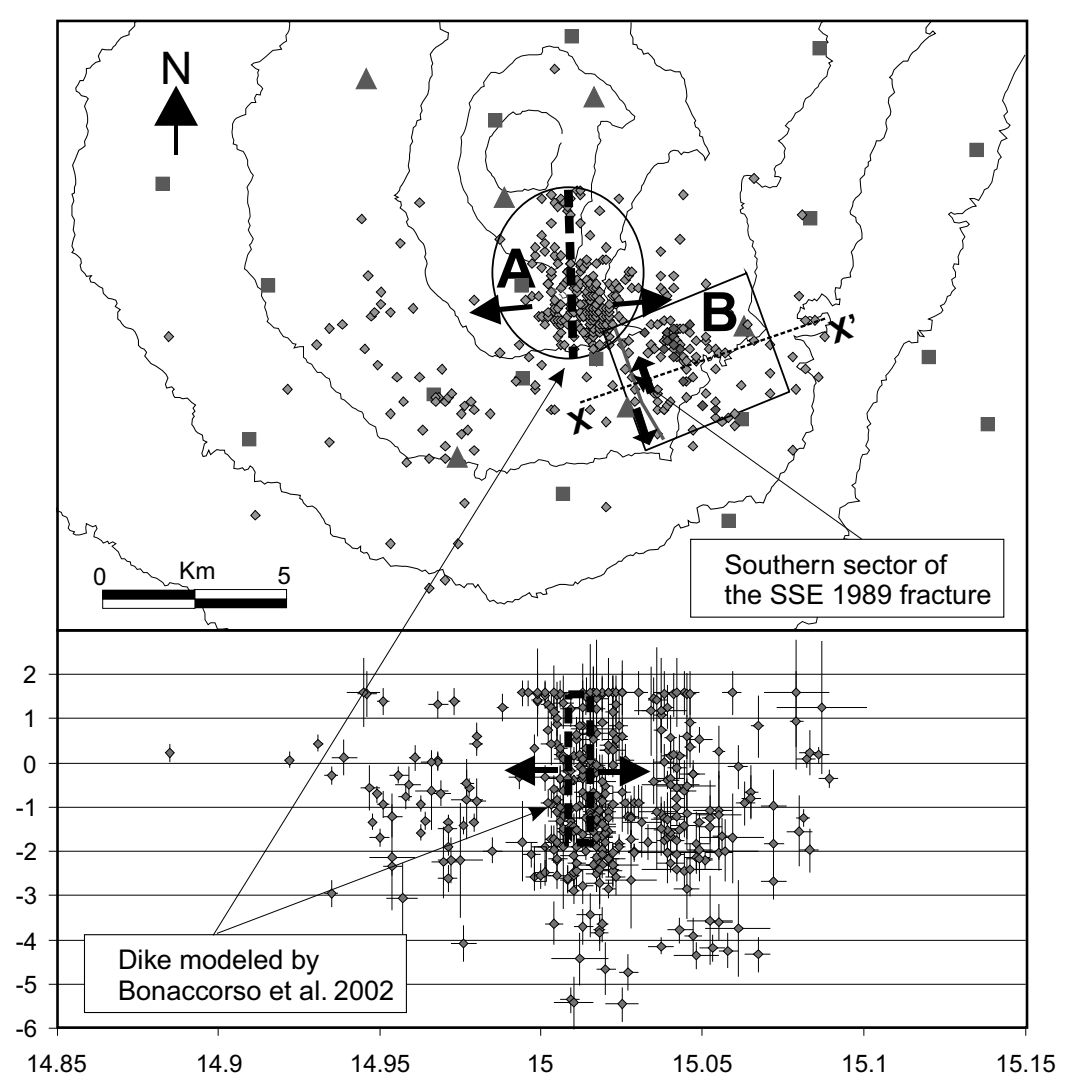

Fig. 8. Epicentral maps and hypocentral W-E cross-section of the earthquakes with $M_{d} \geq 2.0$ recorded between July $12-17,2001$. The southern sector of the 1989 fracture, the 2001 dike modeled by Bonaccorso et al. (2002) and location of main seismic clusters (A and B) are reported. Squares and triangles indicate 1 component (vertical) and 3 component seismic stations respectively.

relating the magnitude to the seismic moment on Mt. Etna area.

Assuming a medium rigidity $(\mu)$ of $10^{11}$ dyne-cm (Bonaccorso and Patanè, 2001) and a discontinuity surface of about $15 \mathrm{~km}^{2}$, it was possible to determine an average slip $\bar{u}$ of about $5.5 \mathrm{~cm}$ using the general relation (Aki, 1966):

$$
M o=\mu \cdot S \cdot \bar{u}
$$

\section{Discussion and Conclusions}

A non-eruptive fracture formed in 1989, on the south flank of Mt. Etna, as a surface effect of a dike intrusion (Bonaccorso and Davis, 1993; Bianco et al., 1998; Del Negro and Ferrucci, 1998).

This discontinuity has successively showed signs of activity; in particular, during the 1991-93 eruption repeated measurements of EDM lines revealed clear deformations of the 1989 fracture area that Bonaccorso et al. (1993) has interpreted as a response to possible magma injection at surface levels.

The 2001 Mt. Etna flank eruption was characterized by a fast upward propagation dike intrusion along a northsouth direction, accompanied by an important seismic activity recorded on 12-17 of July (Bonaccorso et al., 2002; Patanè et al., 2003).

The 2001 eruption was different from the 1989 and 199193 ones, in which the dikes propagated from the craters area southward, usually along preferential directions (NNW-SSE) (Bonaccorso, 2001).
Extensometers showed no variations from their re-installation (May 2000) up to July 2001, while they evidenced clear changes during the final phases of the 2001 dike intrusion (13-17 of July).

Several authors have described intrusion-related activity of surface discontinuities through direct measurements of displacement or geodetic surveys (e.g. Dvorak et al., 1986; Rubin and Pollard, 1988); this paper probably described the first example of a dry fracture continuous dynamic detecting.

Moreover, about $25 \%$ of overall seismic released strain of the 2001 eruption is correlated to the earthquakes located along a narrow band oriented about NNW-SSE, dip 70-80 E, whose extension on the surface is near the southern sector of 1989 fracture.

Extensometer data and seismicity have shown a continuous dynamic of the NNE-SSW structure between 12 and 17 July. Displacement measurements, focal mechanisms, and source parameters indicate a left lateral strike-slip mechanism with a total displacement of 3-4.5 cm measured on the surface and $5.5 \mathrm{~cm}$ estimated for the entire structure (depth of $2-2.5 \mathrm{~km}$ b. s. 1.) by seismicity. A close time relationship between seismicity and surface dynamics has also been evidenced by the coherence of cumulative seismic strain release and displacements trend in Fig. 6.

Data from extensometers and seismic networks were the only ones that may detect the reactivation of NNW-SSE structure; in fact, the marked variations caused by dike propagation on tilt (up to some tens of microradians), GPS and EDM networks (tens of centimeters in slope distances) 

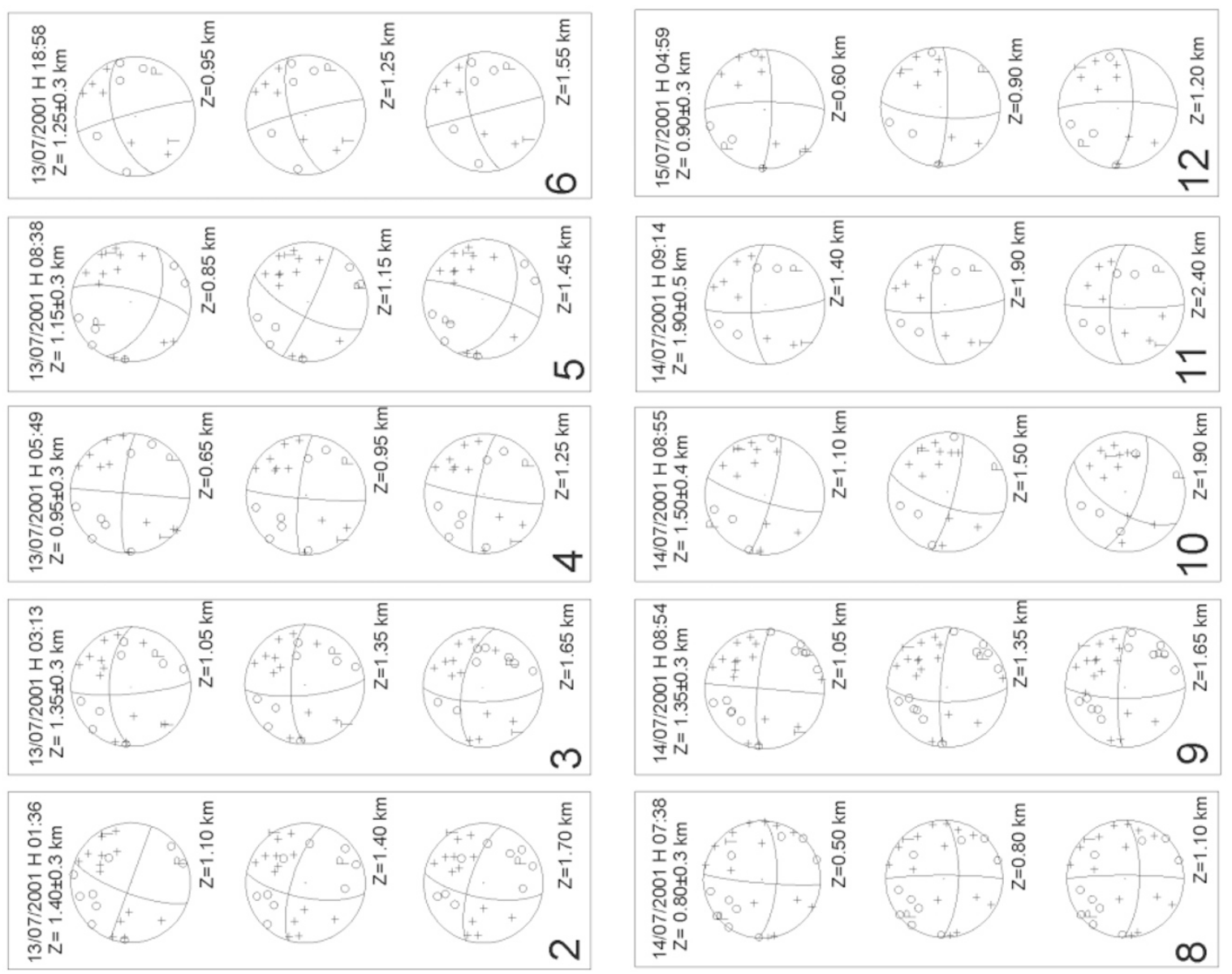

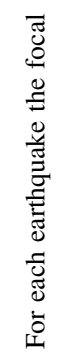
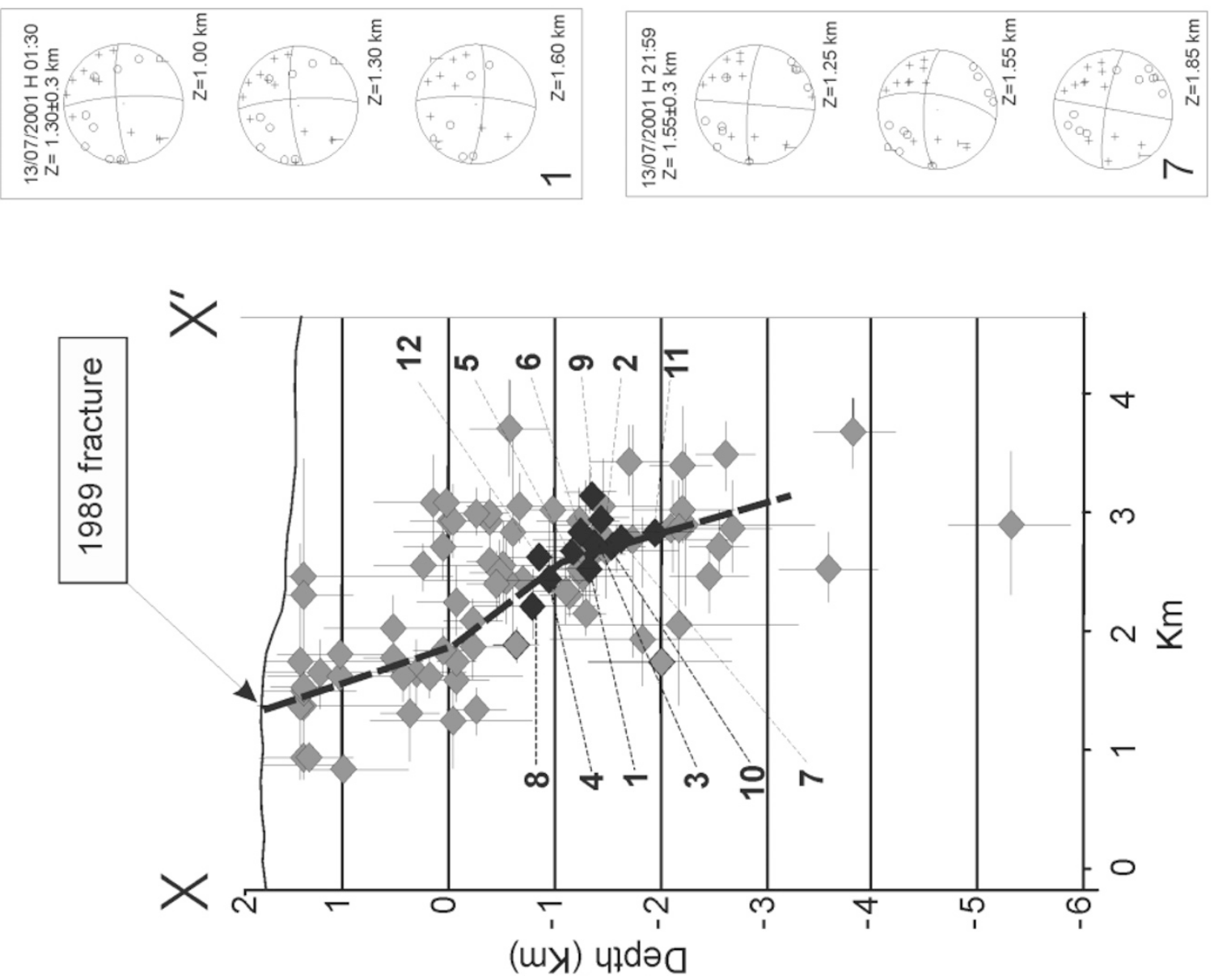

官

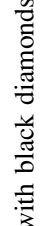

它

品

齐章

范

氕

Uे

है

« 
Table 1. Location parameters of the analyzed earthquakes.

\begin{tabular}{cccccccccccc}
\hline $\mathrm{N}$ & Date & Origin time & $M_{d}$ & Latitude & Longitude & Depth & Gap & No & RMS & ERZ & ERH \\
\hline 1 & $13 / 07 / 01$ & $01: 30: 52.31$ & 2.8 & 37.706 & 15.044 & 1.30 & 57 & 25 & 0.12 & 0.3 & 0.2 \\
2 & $13 / 07 / 01$ & $01: 36: 45.34$ & 2.9 & 37.711 & 15.042 & 1.40 & 41 & 35 & 0.12 & 0.3 & 0.2 \\
3 & $13 / 07 / 01$ & $03: 13: 33.18$ & 3.5 & 37.708 & 15.042 & 1.35 & 40 & 30 & 0.10 & 0.3 & 0.2 \\
4 & $13 / 07 / 01$ & $05: 49: 31.51$ & 2.9 & 37.696 & 15.049 & 0.95 & 86 & 22 & 0.20 & 0.3 & 0.3 \\
5 & $13 / 07 / 01$ & $08: 38: 41.79$ & 2.8 & 37.710 & 15.040 & 1.15 & 51 & 30 & 0.10 & 0.3 & 0.2 \\
6 & $13 / 07 / 01$ & $18: 58: 26.20$ & 2.8 & 37.712 & 15.047 & 1.25 & 46 & 26 & 0.12 & 0.3 & 0.2 \\
7 & $13 / 07 / 01$ & $21: 59: 04.01$ & 3 & 37.708 & 15.040 & 1.55 & 50 & 27 & 0.11 & 0.3 & 0.2 \\
8 & $14 / 07 / 01$ & $07: 38: 14.92$ & 3.4 & 37.692 & 15.051 & 0.80 & 39 & 34 & 0.12 & 0.3 & 0.2 \\
9 & $14 / 07 / 01$ & $08: 54: 08.75$ & 3.5 & 37.709 & 15.042 & 1.35 & 37 & 37 & 0.12 & 0.3 & 0.2 \\
10 & $14 / 07 / 01$ & $08: 55: 51.30$ & 2.6 & 37.710 & 15.040 & 1.50 & 67 & 17 & 0.07 & 0.4 & 0.3 \\
11 & $14 / 07 / 01$ & $09: 14: 54.35$ & 2.6 & 37.710 & 15.033 & 1.90 & 98 & 16 & 0.07 & 0.5 & 0.4 \\
12 & $15 / 07 / 01$ & $04: 59: 39.67$ & 2.8 & 37.704 & 15.042 & 0.90 & 60 & 19 & 0.07 & 0.3 & 0.3 \\
\hline
\end{tabular}

$M_{d}=$ duration magnitude; Gap = azimuthal gap (degrees); No = number of $P$ and $S$ arrivals; RMS $=$ travel-time residual root mean square(s).

(Bonaccorso et al., 2002) precluded the possibility to reveal, on these devices, the minor effects related to the NNW-SSE structure strike movement. Changes of $1.8 \mu \mathrm{rad}$ for the nearest tilt station (CDV in Fig. 2, Table 2) that recorded about $80 \mu \mathrm{rad}$ and $1.9 \mathrm{~cm}$ for the CS3-CS4 EDM line (Fig. 2 and Table 2) that recorded $10.4 \mathrm{~cm}$, are the highest tilt and slope distance variations obtained for a tabular dislocation model located at the southern sector of 1989 fracture, with $4 \mathrm{~km}$ depth, 3.5 length with and $5 \mathrm{~cm}$ of left strike displacement (Okada, 1985).

The dynamic response seems due to the changes in local stress field caused by the dike intrusion rather than a secondary magma intrusion along the NNW-SSE structure (Fig. 8).

Generally, magma intrusion is accompanied by different types of focal mechanisms (sometimes at short distances from each other), as observed for example at Hawaii (Thurber and Gripp, 1988) and at Mt. Usu (Matsumura et al., 1991). This is also the case for the intrusive volume (cluster A in Fig. 8, Patanè et al., 2003).

Instead, a remarkable coherence was found in focal solutions of the main events of B cluster (Fig. 9) that showed left lateral strike-slip mechanisms along a plane ranging from NNW-SSE to NNE-SSW with sub-vertical dip.

Absence of magma in NNE-SSE structure is in agreement with ground deformation results (Bonaccorso et al., 2002) that evidenced a unique stress source, also well supported by the axy-symmetric orientation of $P$-axes for the two "peripheral" (east and west of the main cluster) seismic volumes (Patanè et al., 2003).

Patanè et al. (2003) has suggested that the earthquakes spreading as far as $6 \mathrm{~km}$ east and west of the main seismic cluster have been caused by stress transfer induced by the jerky dike inflation; the results obtained in this paper specify that during the 2001 eruption, the NNE-SSW discontinuity on the high south-eastern sector has represented the main structure of strain release induced by the upward dike intrusion.

Finally this paper confirms that the NNE-SSW disconti-
Table 2. Expected deformation changes for a tabular dislocation model (Okada, 1985) located in correspondence of the southern sector of 1989 fracture, with $4 \mathrm{~km}$ depth, 3.5 length and $5 \mathrm{~cm}$ of left strike displacement at the EDM lines (R. Velardita and B. Puglusi, pers. comm.) and tilt station (Fig. 2) nearest to the fracture (modeled). Recorded 2001 eruptive deformation changes measured at the same EDM lines and tilt station between June and July 2001. Positive values of an EDM line $( \pm[5 \mathrm{~mm}+$ $1 \mathrm{ppm}]$ accuracy) means lengthening. Radial tilt component is directed toward the crater, and a positive signal variation means crater up. The tangential component, is orthogonal to the radial and a positive signal variation means uplift in the anticlockwise direction. CDV station is equipped with a shallow bore-hole tiltmeter with $0.1 \mu \mathrm{rad}$ precision.

\begin{tabular}{ccc}
\hline EDM line & Modeled $(\mathrm{mm})$ & Recorded $(\mathrm{mm})$ \\
\hline CS1-CS2 & -2 & +146 \\
CS1-CS3 & +9 & +138 \\
CS1-CS4 & -4 & +44 \\
CS2-CS3 & +4 & -110 \\
CS2-CS4 & +2 & -155 \\
CS3-CS4 & +19 & +104 \\
\hline CDV Tilt & Modeled $(\mu$ rads $)$ & Recorded $(\mu \mathrm{rads})$ \\
\hline Radial comp. & +1.75 & +40 \\
Tangential comp. & +0.40 & -70 \\
\hline
\end{tabular}

nuity surface evidence (the 1989 fracture) play an important role when new stress critical conditions are reached and appears dynamically to be linked to volcanic activity of the last years.

Acknowledgments. I'd like to thank F. Bianco and E. Fujita for their critical reading of the manuscript and constructive comments. I'm grateful to Giuseppe Laudani who oversaw the reconditioning and maintenance of the extensometer network. I also thank A. Ferro, D. Pellegrino and B. Saraceno for their technical support.

\section{References}

Aki, K., Generation and propagation of $\mathrm{G}$ waves from Niigata earthquake of June 16, 1964, II, Estimation of earthquake moment, released energy, and stress-strain drop from the $\mathrm{G}$ wave spectrum, Bull. Earthquake Res. 
Inst. Univ. Tokyo, 44, 73-88, 1966.

Azzaro, R., Seismicity and active tectonics along the Pernicana Fault, Mt. Etna (Italy), Acta Vulcanologica, 9, 7-14, 1997.

Bianco, F., M. Castellano, and G. Ventura, structural and seismological features of the 1989 syn-eruptive NNW-SSE fracture system at Mt. Etna, Geophys. Res. Lett., 25(10), 1545-1548, 1998.

Bilham, R., Surface slip subsequent to the 24 November 1987 Superstition Hills, earthquake, California, monitored by digital creepmeters, Bull. Seism. Soc. Amer., 79(2), 425-450, 1989.

Bilham, R. and S. Whitehead, Subsurface creep on the Hayward fault, Fremont, California, Geophys. Res. Lett., 24(11), 1307-1310, 1997.

Billi, A., V. Acocella, R. Funiciello, G. Giordano, G. Lanzafame, and M. Neri, Mechanisms for ground-surface fracturing and incipient slope failure associated with the 2001 eruption of Mt. Etna, Italy: analysis of ephemeral field data, J. Volcanol. Geotherm. Res., 122, 281-294, 2003.

Bonaccorso, A., Mt. Etna volcano: modelling of ground deformation patterns of recent eruptions and considerations on the associated precursors, J. Volcanol. Geotherm. Res., 109, 99-108, 2001.

Bonaccorso, A. and P. M. Davis, Dislocation modelling of the 1989 dike intrusion into the flank of Mount Etna, Sicily, J. Geophys. Res., 98, 42614268, 1993.

Bonaccorso, A. and D. Patanè, Shear response to an intrusive episode at Mt. Etna volcano (January 1998) inferred through seismic and tilt data, Tectonophysics, 334, 61-75, 2001.

Bonaccorso, A., G. Falzone, B. Puglisi, R. Velardita, and L. Villari, Ground deformation geodimetric trilateration and borehole tiltmetry, in Mt Etna the 1989 Eruption, edited by F. Barberi, A. Bertagnini, and P. Landi, pp. 44-47, 1990.

Bonaccorso, A., O. Campisi, G. Falzone, S. Gambino, G. Laudani, B. Puglisi, M. Rossi, R. Velardita, and L. Villari, Etna ground deformationEDM and continuous tilt monitoring, in Data Related to Eruptive Activity Unrest Phenomena and Other Observations on the Italian Active Volcanoes in 1991, edited by L. Villari, Acta Vulcanologica, 3, 324-326, 1993.

Bonaccorso, A., O. Campisi, G. Falzone, S. Gambino, G. Laudani, B. Puglisi, M. Rossi, R. Velardita, and L. Villari, Ground deformation monitoring on active volcanoes in Sicily (Italy), Cahiers du Centre Européen de Géodynamique et de Séismologie, 8, 349-357, Luxembourg, 1995.

Bonaccorso, A., F. Ferrucci, D. Patanè, and L. Villari, Fast deformation processes and volcanic activity at Mt Etna (Italy), J. Geophys. Res., 101, 17467-17480, 1996.

Bonaccorso, A., M. Aloisi, and M. Mattia, Dike emplacement forerunning the Etna July 2001 eruption modeled through continuous tilt and GPS data, Geophys. Res. Lett., 29, 13, 10.1029/2001GL014397, 2002.

Budetta, G., M. Grimaldi, and C. Del Negro, Etna gravity and magnetic measurements, in Data Related to Eruptive Activity Unrest Phenomena and Other Observations on the Italian Active Volcanoes in 1991, edited by L. Villari, Acta Vulcanologica, 3, 330-333, 1993.

Budetta, G., M. Grimaldi, and C. Del Negro, Microgravity monitoring of the 1989 SSE Etna fracture, Acta Vulcanologica, 4, 115-118, 1994.

Del Negro, C. and F. Ferrucci, Magnetic history of a dike on Mount Etna (Sicily), Geophys. J. Int., 133, 451-458, 1998.

Dvorak, J. J., A. T. Okamura, T. T. English, J. S. Nakata, M. K. Sako, W. T. Tanigawa, and K. M. Yamashita, Mechanical response of the south flank of Kilauea volcano, Hawaii, to intrusive events along the rift systems, Tectonophysics, 124, 193-209, 1986.

Elsworth, D. and B. Voight, Dike intrusion as a trigger for large earthquakes and the failure of volcano flanks, J. Geophys. Res., 100, 6005-6024, 1995.

Ferrucci, F., Seismic Monitoring at active volcanoes, in Monitoring active volcanoes, edited by B. McGuire, C. Kilburn, and J. Murray, pp. 60-92, 1995.

Ferrucci, F., R. Rasà, G. Gaudiosi, R. Azzaro, and S. Imposa, Mt. Etna: a model for the 1989 eruption, J. Volcanol. Geothem. Res., 56, 35-56, 1993.

Frazzetta, G. and G. Lanzafame, The NE and SE fracture systems, in $M t$ Etna the 1989 eruption, edited by F. Barberi, B. Bertagnini, and P. Landi, pp. 23-29, 1990.

Gresta, S., L. Peruzza, D. Slejko, and G. DiStefano, Inferences on the main volcano-tectonic structures at Mt. Etna (Sicily) from a probabilistic seismological approach, J. Seismol., 2, 105-116, 1998.

Harrison, J. C. and K. Herbst, Thermoelastic strain and tilt revised, Geophys. Res. Lett., 4, 535-537, 1977.

Hirn, A., A. Nercessian, M. Sapin, F. Ferrucci, and G. Wittlinger, Seismic heterogeneity of Mt. Etna: structure and activity, Geophys. J. Int., 105, 139-153, 1991.

INGV-CT, Istituto Nazionale di Geofisica e Vulcanologia, Sezione di Catania, Multidisciplinary approach yields insight into Mt. Etna eruption, EOS, 82(52), 653-656, 2001.

Iwatsubo, E. Y., J. W. Ewert, and T. L. Murray, Monitoring radial crack deformation by displacement meters, in Monitoring Volcanoes: Techniques and Strategies by the Staff of the Cascades Observatory, 1980-90, edited by J. W. Ewert and D. A. Swanson, pp. 95-101, U.S.G.S. Book, 1992.

Lahr, J. C., Hypoellipse Version 2.0*: a computer program for determining local earthquake hypocentral parameters, magnitude, and first motion pattern, United States Department of the Survey Menlo Park, California, Open File Report, 89-116, 1989.

Lanzafame, G., M. Neri, V. Acocella, A. Billi, R. Funiciello, and G. Giordano, Structural features of the July-August 2001 Mount Etna eruption: evidence for a complex magma supply system, J. Geol. Soc., 160, 531544, 2003.

Lee, J., F. Jeng, H. Chu, J. Angelier, and J. Hu, A rod-type creepmeter for measurement of displacement in active fault zone, Earth Planets Space, 52(5), 321-328, 2000.

LoGiudice, E., G. Patanè, R. Rasà, and R. Romano, The structural framework of Mt. Etna, Mem. Soc. Geol. It., 23, 125-158, 1982.

Matsumura, S., T. Ohkubo, and M. Imoto, Seismic swarm activity in and around the Izu Peninsula preceding the volcanic eruption of July 13, 1989, J. Phys. Earth, 39, 93-106, 1991.

Monaco, C., P. Tapponnier, L. Tortorici, and P. Y. Gillot, Late Quaternary slip rates on the Acireale-Piedimonte normal faults and tectonic origin of Mt. Etna (Sicily), Earth Planet. Sci. Letters, 147, 125-139, 1997.

Obrizzo, F., Etna Vertical ground movements by precise levelling, in Geophisical Monitoring of the Italian Active Volcanoes 1993-1995, edited by P. Gasparini, Acta Vulcanologica, 10(1), 170-174, 1998.

Obrizzo, F., Etna Vertical ground movements by precise levelling. September 1995-September 1996, in Data Related to Eruptive Activity Unrest Phenomena and Other Observations on the Italian Active Volcanoes in 1996, edited by L. Villari, Acta Vulcanologica, 12(1-2), 84-85, 2000.

Obrizzo, F., C. Del Gaudio, M. Ferri, C. Ricco, V. Sepe, and G. Luongo, Etna Ground deformation-Precise levelling, in Data Related to Eruptive Activity Unrest Phenomena and Other Observations on the Italian Active Volcanoes in 1991, edited by L. Villari, Acta Vulcanologica, 3, 326-327, 1993.

Okada, Y., Surface deformation due to shear and tensile faults in a halfspace, J. Geophys. Res., 75, 1135-1154, 1985.

Patanè, D. and E. Privitera, Seismicity related to 1989 and 1991-93 Mt. Etna (Italy) eruptions: kinematic constraints by FPS analysis, J. Volcanol. Geotherm. Res., 109, 77-98, 2001.

Patanè, D., E. Privitera, F. Ferrucci, and S. Gresta, Seismic activity leading to the 1991-93 eruption of Mt. Etna and its tectonic implications, in The 1991-93 Etna Eruption, edited by L. Villari, Acta Vulcanologia, 4, 4756, 1994.

Patanè, D., F. Ferrucci, and S. Gresta, Leggi di scala e parametri di sorgente per terremoti all'Etna, Atti 12 Conv. Ann. GNGTS, 925-928, 1995.

Patanè, D., E. Privitera, S. Gresta, S. Alparone, A. Akinci, G. Barberi, L. Chiaraluce, O. Cocina, S. D’Amico, P. DeGori, G. DiGrazia, S. Falsaperla, F. Ferrari, S. Gambino, E. Giampiccolo, H. Langer, V. Maiolino, M. Moretti, A. Mostaccio, C. Musumeci, D. Piccinini, D. Reitano, L. Scarfi, S. Spampinato, A. Ursino, and L. Zuccarello, Seismological features and kinematic constrains for the July-August 2001 lateral eruption at Mt. Etna volcano, Italy, Annals of Geophysics, 46, 599-608, 2003.

Reasenberg, P. A. and D. Oppenheimer, FPFIT, FPPLOT AND FPPAGE: fortran computer porgrams for calculating and displaying earthquake fault plane solutions, U.S. Geol. Sur., Open file Report, 85-739, 1985.

Richter, C. F., Elementary Seismology, W. H. Freeman, San Francisco, pp. 135-149, 1958.

Rubin, A. M. and D. D. Pollard, Dike-induced faulting in rift zones of Iceland and afar, Geology, 16, 413-417, 1988.

Thurber, C. and A. E. Gripp, Flexure and seismicity beneath the south flank of Kilauea Volcano and tectonic implications, J. Geophys. Res., 93, 42714278, 1988.

Ukawa, M. and H. Tsukahara, Earthquake swarms and dike intrusions off the east coast of Izu Peninsula, central Japan, Tectonophysics, 253, 285303, 1996.

S. Gambino (e-mail: gambino@ct.ingv.it) 